\title{
Detection of Volatile Organic Compounds with Secondary Electrospray Ionization and Proton Transfer Reaction High-Resolution Mass Spectrometry: A Feature Comparison
}

\author{
Bruderer, Tobias ; Gaugg, Martin T ; Cappellin, Luca ; Lopez-Hilfiker, Felipe ; Hutterli, Manuel ; \\ Perkins, Nathan ; Zenobi, Renato ; Moeller, Alexander
}

\begin{abstract}
The analysis of volatiles is of high relevance for a wide range of applications from environmental air sampling and security screening to potential medical applications. High-resolution mass spectrometry methods offer a particularly wide compound coverage, sensitivity, and selectivity. Online approaches allow direct analysis in real time without the need for sample preparation. For the first time, we systematically compared the analysis of volatile organic compounds with secondary electrospray ionization (SESI) and proton transfer reaction (PTR) high-resolution mass spectrometry. The selected instruments had comparable mass resolving powers with $\mathrm{m} / \Delta \mathrm{m} \quad 15000$, which is particularly suitable for nontargeted analysis, for example, of exhaled breath. Exhalations from 14 healthy adults were analyzed simultaneously on both instruments. In addition, 97 reference standards from nine chemical classes were analyzed with a liquid evaporation system. Surprisingly, in breath, we found more complementary than overlapping features. A clear mass dependence was observed for each method with the highest number of detected $\mathrm{m} / \mathrm{z}$ features for SESI in the high mass region $(\mathrm{m} / \mathrm{z}=150-250)$ and for PTR in the low mass region $(\mathrm{m} / \mathrm{z}$ $=50-150)$. SESI yielded a significantly higher numbers of peaks (828) compared to PTR (491) among a total of 1304 unique breath $\mathrm{m} / \mathrm{z}$ features. The number of signals observed by both methods was lower than expected (133 features) with 797 unique SESI features and 374 unique PTR features. Hypotheses to explain the observed mass-dependent differences are proposed.
\end{abstract}

DOI: https://doi.org/10.1021/jasms.0c00059

Posted at the Zurich Open Repository and Archive, University of Zurich

ZORA URL: https://doi.org/10.5167/uzh-191242

Journal Article

Accepted Version

Originally published at:

Bruderer, Tobias; Gaugg, Martin T; Cappellin, Luca; Lopez-Hilfiker, Felipe; Hutterli, Manuel; Perkins, Nathan; Zenobi, Renato; Moeller, Alexander (2020). Detection of Volatile Organic Compounds with Secondary Electrospray Ionization and Proton Transfer Reaction High-Resolution Mass Spectrometry: A Feature Comparison. Journal of the American Society for Mass Spectrometry, 31(8):1632-1640.

DOI: https://doi.org/10.1021/jasms.0c00059 


\title{
Detection of volatile organic compounds with SESI and PTR high-resolution mass spectrometry: a feature comparison
}

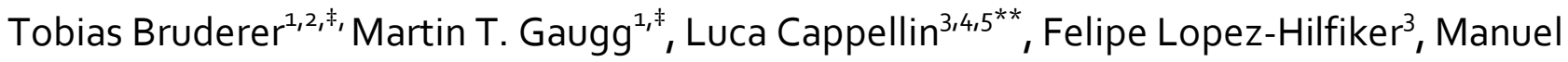 \\ Hutterli ${ }^{3}$, Nathan Perkins ${ }^{6}$, Renato Zenobi ${ }^{1, *}$ and Alexander Moeller ${ }^{2}$ \\ ${ }^{1}$ Department of Chemistry and Applied Biosciences, Swiss Federal Institute of Technology, 8093 Zurich, Switzerland. ${ }^{2}$ \\ Division of Respiratory Medicine, University Children's Hospital Zurich and Children's Research Center Zurich, 8032 \\ Zurich, Switzerland. ${ }^{3}$ TOFWERK AG, 3645 Thun, Switzerland. ${ }^{4}$ Dipartimento di Scienze Chimiche, Università degli Studi \\ di Padova, 35131 Padua, Italy. ${ }^{5}$ Research and Innovation Centre, Fondazione Edmund Mach, 38010 S. Michele a/A , Italy. ${ }^{6}$ \\ Clinical Chemistry and Biochemistry, University Children's Hospital Zurich, 8032 Zurich, Switzerland.
}

Email*zenobi@org.chem.ethz.ch,**luca.cappellin@unipd.it, $\neq$ Equal contribution

ABSTRACT

The analysis of volatiles is of high relevance for a wide range of applications from environmental air sampling, security screening to potential medical applications. Highresolution mass spectrometry methods offer a particular wide compound coverage, sensitivity and selectivity. On-line approaches allow direct analysis in real time without the need for sample preparation. For the first time, we systematically compared the analysis of volatile organic compounds with Secondary Electrospray Ionization (SESI) and Proton Transfer Reaction (PTR) high-resolution mass spectrometers. The selected instruments had comparable mass resolving power with $15^{\prime} 000 \mathrm{~m} / \Delta \mathrm{m}$ or higher, which is particularly suitable for non-targeted analysis, for example, of exhaled breath. Exhalations from 14 healthy adults were analyzed simultaneously on both instruments. In addition, 97 reference standards from nine chemical classes were analyzed with a liquid evaporation system. Surprisingly, in breath, we reported more complementary than overlapping features. A clear mass dependence was observed for each method with the highest number of detected $\mathrm{m} / \mathrm{z}$ features for SESI in the high mass region $(\mathrm{m} / \mathrm{z}=150-250)$ and for PTR in the low mass region $(\mathrm{m} / \mathrm{z}=50-150)$. SESI yielded a significantly higher numbers of peaks (828) compared to PTR (491) among a total of 1304 unique breath $\mathrm{m} / \mathrm{z}$ features. The number of signals observed by both methods was lower than expected (133 features) with 797 unique SESI features and 374 unique PTR features. Hypotheses to explain the observed mass-dependent differences are proposed. 


\section{Introduction}

The analysis of volatile organic compounds allows for a wide range of applications from environmental air sampling [1], to security applications [2] to breath analysis for medical diagnosis [3]. For on-line detection, mass spectrometry based methods allow the detection of the highest number of compounds from a wide range of chemical classes [4]. There are three principal methods for mass spectrometry based on-line analysis of volatiles: Selected Ion Flow Tube mass spectrometry (SIFT-MS), Proton Transfer Reaction (PTR-MS) and Secondary Electrospray Ionization (SESI-MS). Resolving powers of $\mathrm{m} / \Delta \mathrm{m} 15^{\prime} 000$ or higher are particularly important for comprehensive, non-targeted analysis of complex volatile mixtures without a pre-separation step. [5]. Such highresolution instruments are available for SESI and very recently also for PTR. For SESI, high-resolution TOF systems $\left(\mathrm{m} / \Delta \mathrm{m}>10^{\prime} 000\right)$ or very high-resolution instruments such as Orbitraps with $\mathrm{m} / \Delta \mathrm{m}$ up to $280^{\prime} 000$ are commonly being used. Most PTR time-of-flight (TOF) instruments have a resolving power $(\mathrm{m} / \Delta \mathrm{m})$ of up to $6^{\prime} 000$ [6] and only a recently developed instrument is capable of a mass resolving power $\mathrm{m} / \Delta \mathrm{m}>10^{\prime} 000$ [7]. This is the first breath analysis study with this recently developed highresolution PTR-TOF instrument.

The motivation for this study was that SESI-TOF and PTR-TOF methods have not yet been compared for their suitability to analyze complex mixtures of volatile organic compounds (i.e. of exhaled breath) in a comprehensive, non-targeted manner. The recently developed PTR-TOF instrument with a mass resolving power comparable to available SESI-TOF instruments allowed for the first time to compare both methodologies at comparable high mass resolving powers $\left(\mathrm{m} / \Delta \mathrm{m} \geq 15^{\prime} 000\right)$. The goal of this work was to compare the differences between both methods based on an identical sample (i.e. exhaled breath), which was simultaneously analyzed with both methods. It was not the aim of this work to, e.g., investigate the reproducibility of each method for breath, which would be a work of its own (see, for example, [8] for SESI-HRMS). A significant overlap in detected $\mathrm{m} / \mathrm{z}$ features was expected for both methodologies based on similar reported sensitivities (down to ppt levels) and the same reported principal ion species (i.e., protonated ions $[\mathrm{M}+\mathrm{H}]^{+}$). Some differences were expected due to possible differences in fragment formation and the possibility of forming additional adducts for SESI (e.g. sodium adducts).

The aims of this systematic, comparative study were to: i) compare the detected breath $\mathrm{m} / \mathrm{z}$ features for both methods, ii) to compare the ability to detected different chemical classes, iii) to investigate the formation of different adduct and fragments and iv) to investigate differences between both methodologies with the overall aim to determine the suitability of each technology to analyze volatile organic compounds in a comprehensive, non-targeted manner.

\section{Methods}

\section{Instrumentation}

For this comparison study the following two setups were selected: a SESI ion source mounted on a Q-TOF instrument $\left(22^{\prime} 000 \mathrm{~m} / \Delta \mathrm{m}\right.$ at $\left.\mathrm{m} / \mathrm{z} 205.195\right)$ and a portable PTR-TOF instrument with highest currently available mass resolution for PTR instruments $\left(\mathrm{m} / \Delta \mathrm{m}=15^{\prime} 000\right.$ at $\mathrm{m} / \mathrm{z}$ 205.195). The samples investigated were exhaled breath from 14 healthy adults, sampled on-line, simultaneously on both instruments. In addition, due to limited amount of investigated chemical classes present within the current literature for SESI, reference standards from nine chemical classes were measured with a liquid evaporation system.

Figure 1: Schematics for SESI and PTR time-of-flight (TOF) high-resolution mass spectrometry. 1) Schematic for a Super SESI ion source mounted on a Q-TOF instrument and b) Schematic for the Vocus PTR-TOF.
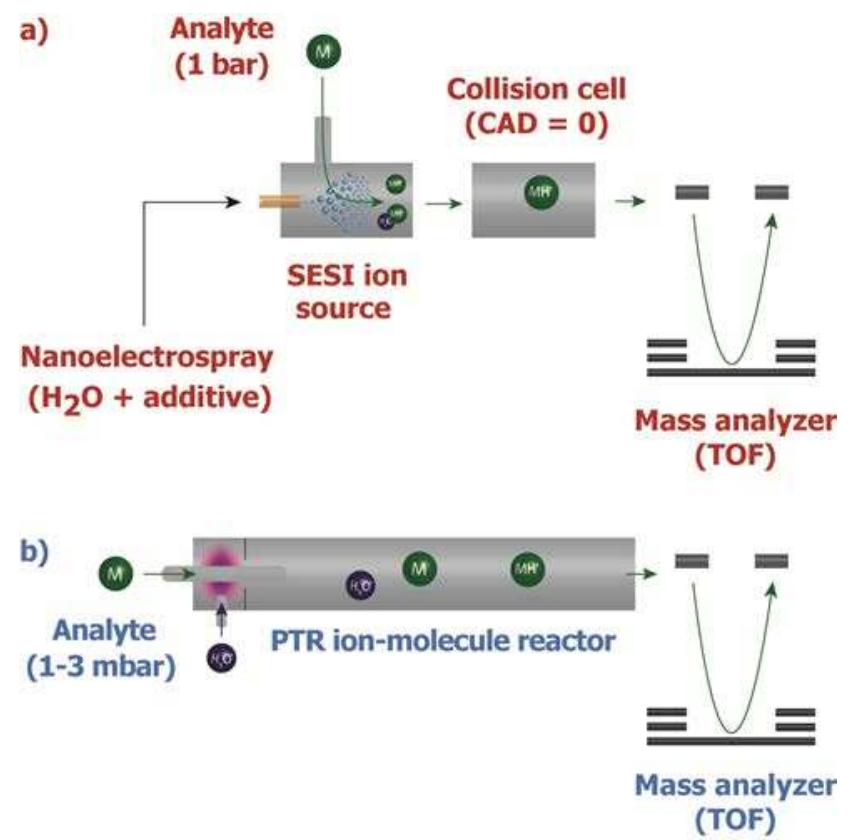

A high-resolution PTR-TOF instrument (Vocus PTRTOF, TOFWERK AG, Thun, Switzerland) was used for this study. This portable instrument was temporarily moved to the University Children's Hospital Zurich to compare the PTR instrument with a Super SESI ion source (FIT, Malaga, Spain) mounted on a Q-TOF instrument (Triple TOF 5600+, Sciex, Toronto, Canada). The schematics for ionization with PTR and SESI are shown in Figure 1.

The instrument settings for the SESI-TOF instrument were: $m / z$ range $=50-500$, ion spray voltage: $4.5 \mathrm{kV}$, curtain gas GS1 $=10$, collision energy $=10 \mathrm{eV}$, collision gas set at $\mathrm{CAD}=0$ with a scan rate of 1 spectrum per second. The sampling line, core and curtain gas for the SESI ionization source were heated to $130{ }^{\circ} \mathrm{C}$. The electrospray fluid for the SESI nanospray was composed of ultrapure 
water with $0.1 \%(\mathrm{v} / \mathrm{v})$ formic acid. TaperTip nanospray capillaries with tip diameters of $20 \mu \mathrm{m}$ and $50 \mathrm{~cm}$ length were cut to $40 \mathrm{~cm}$ length before analysis (TT360-20-20-N5, MS Wil, Netherlands). An overpressure of 1.5 bar was applied to the electrospray reservoir of the SESI ion source. The flow at the exhaust of the ionization source was measured.

The instrument settings for the Vocus PTR-TOF instrument were $\mathrm{m} / \mathrm{z}$ range $=0-500$, scan rate: 1 spectrum per second, focusing ion molecule reactor conditions were: 1.5 mbar, $500 \mathrm{~V} \mathrm{DC}$ voltage, $25{ }^{\circ} \mathrm{C}, 1.3 \mathrm{MHz} \mathrm{RF}$ frequency operated at an amplitude of $450 \mathrm{~V}$. The inlet and the ion molecule reactor of the PTR were not heated. Instrumental concentration calibrations using a standard cylinder containing 1 ppmv benzene, toluene, and xylene (ApelRiemer, USA) was performed daily, checking that sensitivity changes were within $5 \%$ between experiment days. The background sample was clean medical air humidified at $37^{\circ} \mathrm{C}$, and simultaneously measured with SESI and PTR.

The two instruments were connected together for simultaneous on-line analysis. Single-use mouthpieces were connected to a Teflon adapter, which was split down-stream into two sampling lines, each connected to one of the two instruments. The teflon adapter had two additional ports, one connected to a manometer for biofeedback and an additional $3 \mathrm{~mm}$ hole, which served as an overflow exhaust. The sampling lines were tubes made of stainless steel with a highly inert coating (SilcoNert 2000) which were heated to $130^{\circ} \mathrm{C}$ to minimize carryover and to allow rapid washout by heating and nitrogen back flush through the sampling lines.

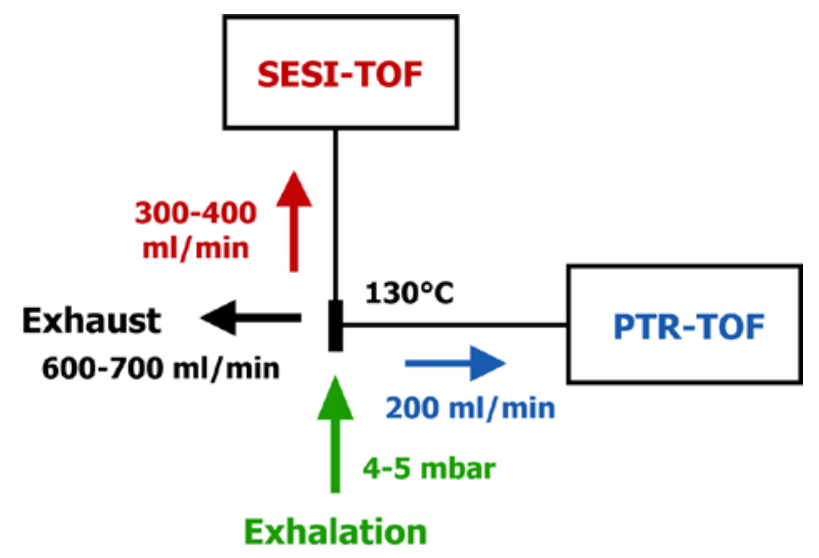

Figure 2: Setup for simultaneous analysis of VOCs from breath with SESI and PTR time-of-flight high-resolution mass spectrometry.

The amount of detected signal depends for both methods on the concentrations and not on the amounts of compounds. As such, the flows can be different for each instrument. They should however be in the optimal range for each instrument which was between $300-400 \mathrm{ml} / \mathrm{min}$ for the used SESI-TOF and $200 \mathrm{ml} / \mathrm{min}$ for the PTR-TOF (see figure 2). The flows were measured with a mass flow controller (F-201EV, Bronkhorst, Ruurlo, Netherlands) and were controlled by an exhalation pressure of 4-5 mbar by biofeedback from a manometer and recorded between 300$400 \mathrm{ml} / \mathrm{min}$ for SESI and controlled with an integrated flow controller at $200 \mathrm{ml} / \mathrm{min}$ for PTR.

\section{Healthy human subjects}

A total of $\mathrm{n}=22$ healthy, non-smoking adults were enrolled in this study. The study protocol was reviewed and approved by the cantonal ethics committee. The initial eight measurements were excluded because, the Vocus PTR-MS was not set at its highest resolving power. Data analysis was done with $\mathrm{n}=14$ subjects measured at highest resolving power $\left(\mathrm{m} / \Delta \mathrm{m}=15^{\prime}, 000\right)$.

The participants were seated comfortably on a chair. They were asked to exhale naturally at an exhalation pressure between 4-5 mbar based on biofeedback as indicated by the manometer, and to stop before breathing became uncomfortable. The first couple of exhalations were not recorded and were used to train the participants until the TIC was comparable between exhalations. These exhalations also served as washout (with humidified gas, i.e. breath) and to condition sampling lines between subjects. Once comparable exhalations were reached, five exhalations were acquired and used for further data analysis (see data analysis section). Samples were collected during a single session from each subject during three consecutive days.

\section{Liquid standards evaporation}

A wide range of chemical classes have been investigated in detail with PTR while only some classes have been investigated systematically with SESI. Therefore, we did evaporation measurements of liquid standards for SESI for the following nine compound classes: aldehydes, ketones, aromatic compounds, acids, amino acids, esters, terpenoids, alkanes and alkenes (monoenes).

A set of 97 compounds from nine chemical classes were measured with liquid standard evaporation system with SESI. For evaporation, a miniature custom-made evaporator system was used. It consisted of a SilcoNert 2000 treated stainless steel Swagelok T-piece heated at $130{ }^{\circ} \mathrm{C}$ and a small volume Teflon $\mathrm{T}$-piece chamber $(1 \mathrm{ml})$. Its content could be injected in the flow stream of $350 \mathrm{ml} / \mathrm{min}$ humidified medical air. The water in the glass bottle used as a humidifier and the supply Teflon lines in and out of the humidifier were kept at $37^{\circ} \mathrm{C}$ by a heated aluminum casing. The whole evaporator/humidifier system consisted of highly inert materials (glass, Teflon and SilcoNert 2000 treated stainless steel surfaces) and could easily be cleaned. Sample volumes of $5 \mu \mathrm{l}$ were spotted on disposable Whatman filter papers (Merck, Darmstadt, Germany), evaporated for one minute in the small chamber before manual injection into the stream of humidified air and the SESI-TOF analyzer. A 
blank filter paper sample was measured before each standard measurement. The aldehyde mixture was measured at the beginning, in the middle and at the end of the batch, and yielded a coefficient of variation $<10 \%$.

\section{Data analysis}

Data processing was done in the same manner for both instruments. The SESI-MS data were acquired as proprietary .wiff files, converted to .mzXML with ProteoWizard [10], and imported into Matlab (Matlab R2018b, The Mathworks Inc., Natick/MA, USA). The PTRMS data were acquired in .h5 format and imported into Matlab.

Data processing was done with Matlab. The investigated mass range was $m / z=50-500 . M / z$ values below 50 were not acquired for SESI and excluded for PTR measurements. Data interpolation was done with steps of $0.00025 \mathrm{u}$. The exhalation phases were determined by approximation when the TIC was higher than the mean TIC. This was considered appropriate, since the aim of this study was to directly compare the two technologies, without making any statements about the metabolism of the subjects.

The baseline was adjusted to minimize detector artifacts and saturated signals were removed for the PTR measurements for acetone and its isotopes $(\mathrm{m} / \mathrm{z}=59.06$ 60.00, $\mathrm{m} / \mathrm{z}=60.11-60.93$ and $\mathrm{m} / \mathrm{z}=61.10-61.97)$. Peak picking was done with the proprietary Matlab function mspeaks with standard parameters and a height filter $\geq 10$ cps. The average intensity was calculated for each $\mathrm{m} / z$ value and subject for all $n=14$ measurements by peak integration between the peak bounds calculated by the mspeaks function. The time traces for all $\mathrm{m} / \mathrm{z}$ values were calculated for each breath and background sample. The following filters were applied for selection of the final breath $\mathrm{m} / \mathrm{z}$ values: 1) No overlap between the $99 \%$ confidence intervals for the signal intensities for breath and background samples. 2) The average breath intensities had to be at least two times higher in breath than for the background samples. 3) Each $m / z$ peak had to be detected in at least 3 of the 14 subjects. We aimed to cover a broad range of the human volatilome, but also considered compounds that were only present in a subset of people. The resulting $\mathrm{m} / \mathrm{z}$ values and average intensities for the SESI and PTR measurements are listed in Table $\mathrm{S} 1$.

The data from the evaporated reference standard measurements were imported in the same manner as the data from the breath samples. The $m / z$ values of interest were extracted with \pm 5 ppm for the five most intense scans, which was deemed appropriate for the short peak width for the standard samples. The following filters were applied: 1) an average intensity higher than $100 \mathrm{cps}, 2$ ) an intensity base peak difference between standard and blank higher than $100 \mathrm{cps}$ and 3) an intensity ratio standard vs. blank $>2$. The resulting breath $\mathrm{m} / \mathrm{z}$ values for the investigated isotopes, adducts and losses for the evaporated reference standards are listed in Table S2.

\section{Chemicals and solvents}

LC-MS grade water (Optima, Fluka, Munich, Germany) and $0.1 \%$ formic acid (LC-MS grade, Merck, Darmstadt, Germany) were used for establishing the electrospray in the SESI source. LC-MS grade water was used to humidify clean medical air. The cleaning solvent for instrument surfaces was a mixture of $1 / 1 \mathrm{v} / \mathrm{v}$ LC-MS grade methanol (Optima, Fluka, Munich, Germany) and LC-MS grade water. Compound standard mixtures were provided by the Berner Fachhochschule (Biel, Switzerland). The 97 reference standards were from nine chemical classes, and their CAS numbers and amounts (mmol) used for the evaporation experiments are listed in Table S3.

\section{Results and Discussion}

\section{Differences between SESI and PTR}

Both instruments are comparable in terms of mass resolving power (Table 1) and reported sensitivity (down to the ppt level [7,9]. For PTR, the ionization mechanism is precisely known, which allows the calculation of gas-phase concentrations for the volatiles of interest [10]. However, such calculations are only reliable if the formation of fragments is known from measuring a reference standard of the compound of interest [11]. Quantitative methods have been developed for a range of compounds for PTR but not for SESI. The principal reported ion species for PTR is the singly charged protonated molecule $[\mathrm{M}+\mathrm{H}]^{+}$, and fragmentation can be significant for PTR [12].

The ionization mechanism for SESI is not well known. There have been only a few fundamental mechanistic studies to investigate the principle of SESI ionization [1315]. The principal ion species for SESI are assumed to be protonated molecules similar to PTR. A range of adducts have been reported in the literature such as water, sodium and potassium adducts for positive ion mode, or formate adducts for negative ion mode. Fragmentation such as water and ammonia losses can occur. The formation of different adducts and losses in SESI have not been investigated systematically yet. As opposed to PTR, very high mass compounds and very polar compounds have been reported with SESI [4].

Some key differences between the two methods are highlighted in figure 1: SESI operates at ambient pressure while PTR operates at 1-3 mbar. The breath sample that flows into the PTR (about $100 \mathrm{ml} / \mathrm{min}$ ) is mixed with water vapor (about $30 \mathrm{ml} / \mathrm{min}$ ). This results in a sample dilution for PTR of about $25 \%$. The content of added water vapor is high compared to the air/breath sample which makes the unique configuration of the investigated Vocus PTR-TOF largely independent of the humidity of the sample. The ionization regions for PTR and SESI have very different 
dimensions. For the PTR instrument, ionization takes place in a comparatively long drift tube $(10 \mathrm{~cm})$, compared to a much more compact ionization region in SESI sources (est. $<1 \mathrm{~cm}$ ). In addition, any ion optical elements in the flight path from the ionization to the detector can impact the detected $\mathrm{m} / \mathrm{z}$ features. We observed that the standard collision gas value $(\mathrm{CAD}=6)$ for the Triple TOF $5600+$ instrument resulted in significant fragmentation, which was absent without collision gas $(\mathrm{CAD}=0)$. Thus, most clinical breath analysis studies are nowadays performed with CAD $=0$ [8]. It must be mentioned in this context that the operation of the Q-TOF instrument with this setting requires manual sensitivity tuning. In addition, fast switching between full scan and product ion scan is not possible anymore. However, this second limitation is not an issue for breath analysis in full scan mode and only becomes relevant for compound identification experiments.

Table 1: Key differences for the integrated Vocus PTRTOF instrument and a Super SESI ion source mounted on a Triple-TOF 5600+ Q-TOF high-resolution mass spectrometer. The $\mathrm{m} / \mathrm{z}$ value 205.195 for sesquiterpene $\left[\mathrm{C}_{15} \mathrm{H}_{24}+\mathrm{H}\right]^{+}$was selected as reference mass to compare the resolving power of both instruments.

\begin{tabular}{|c|c|c|}
\hline & PTR-TOF & SESI-TOF \\
\hline $\begin{array}{l}\text { Mass resolving power } \\
\mathrm{m} / \Delta \mathrm{m}(\mathrm{m} / z=\mathbf{2 0 5 . 1 9 5})\end{array}$ & $15^{\prime} 000$ & $22^{\prime} 000$ \\
\hline Reported sensitivity & ppt & ppt \\
\hline Compound coverage & $\begin{array}{l}\text { Volatiles and semi- } \\
\text { volatiles }\end{array}$ & $\begin{array}{l}\text { Volatiles and semi- } \\
\text { volatiles (incl. very polar } \\
\text { and high-mass } \\
\text { compounds) }\end{array}$ \\
\hline $\begin{array}{l}\text { Expected principal } \\
\text { ion species }\end{array}$ & {$[\mathrm{M}+\mathrm{H}]^{+}$} & {$[\mathrm{M}+\mathrm{H}]^{+}$} \\
\hline $\begin{array}{l}\text { Other expected ion } \\
\text { species }\end{array}$ & $\begin{array}{l}\text { Fragments, clusters } \\
\text { possible }\end{array}$ & $\begin{array}{l}\text { Adducts, clusters } \\
\text { some fragments }\end{array}$ \\
\hline $\begin{array}{l}\text { Ionization } \\
\text { mechanism }\end{array}$ & Known & Unknown \\
\hline Quantification & $\begin{array}{l}\text { Concentrations can } \\
\text { be calculated } \\
\text { (if fragments have } \\
\text { been characterized) }\end{array}$ & $\begin{array}{l}\text { Concentration calc. } \\
\text { not possible (ionization } \\
\text { mechanism not known) }\end{array}$ \\
\hline
\end{tabular}

\section{Mass spectra comparison for SESI and PTR}

An overlay of the mass spectra for the 14 subjects shows clear differences in sensitivity for both methods, as shown in figure 3. Significantly higher intensities are observed for PTR than SESI for the low mass region $(\mathrm{m} / z=50-150)$; particularly for the very low mass region $(<100 \mathrm{~m} / \mathrm{z})$. The following $\mathrm{m} / \mathrm{z}$ features showed very high intensities for PTR which were even above the y-axes limit selected for figure $1: \mathrm{m} / \mathrm{z}=59.049$ (acetone) with highest intensity of $2.4 \times 10^{7}$ cps, $m / z=60.052\left({ }^{13} \mathrm{C}\right.$ acetone isotopomer $)$ with $1.4 \times 10^{6}$ cps., $m / z=77.059$ (acetone water cluster) with $6.5 \times 10^{5} \mathrm{cps}$ and $m / z=69.069$ (isoprene) with $3.0 \times 10^{5} \mathrm{cps}$. Significantly higher intensities can be observed for most $\mathrm{m} / z$ features in the high mass regions for SESI.

The differences between both methods are shown more clearly with an overlay of selected mass regions for the 14 subjects for each method (figure 4). The intensities for pyridine [11], a well-known marker from the aroma of roasted coffee beans, and endogenous indole were quite comparable for both methods. However, the intensity of isoprene was significantly higher for PTR than for SESI (top panel of figure 4). All three example compounds showed good correlations between SESI and PTR analysis with a Spearman's correlation coefficient of $R_{\text {sp }}$ of 0.87 0.96 and adjusted $R^{2}=0.7-0.8$ (mid panel of figure 4). Furthermore, three different exemplary $\mathrm{m} / \mathrm{z}$ ranges are shown (bottom panel of figure 4). The $\mathrm{m} / \mathrm{z}$ range $99.00-$ 99.13 was selected as an example to illustrate the different ionization behavior for SESI and PTR. In the high mass range, only few peaks could be detected with PTR, which is illustrated by the example $\mathrm{m} / \mathrm{z}$, range $195.12-195.21$. For the very high mass range most peaks could only be detected with SESI which is illustrated by the example $\mathrm{m} / \mathrm{z}$ range $338.80-339.02$. 

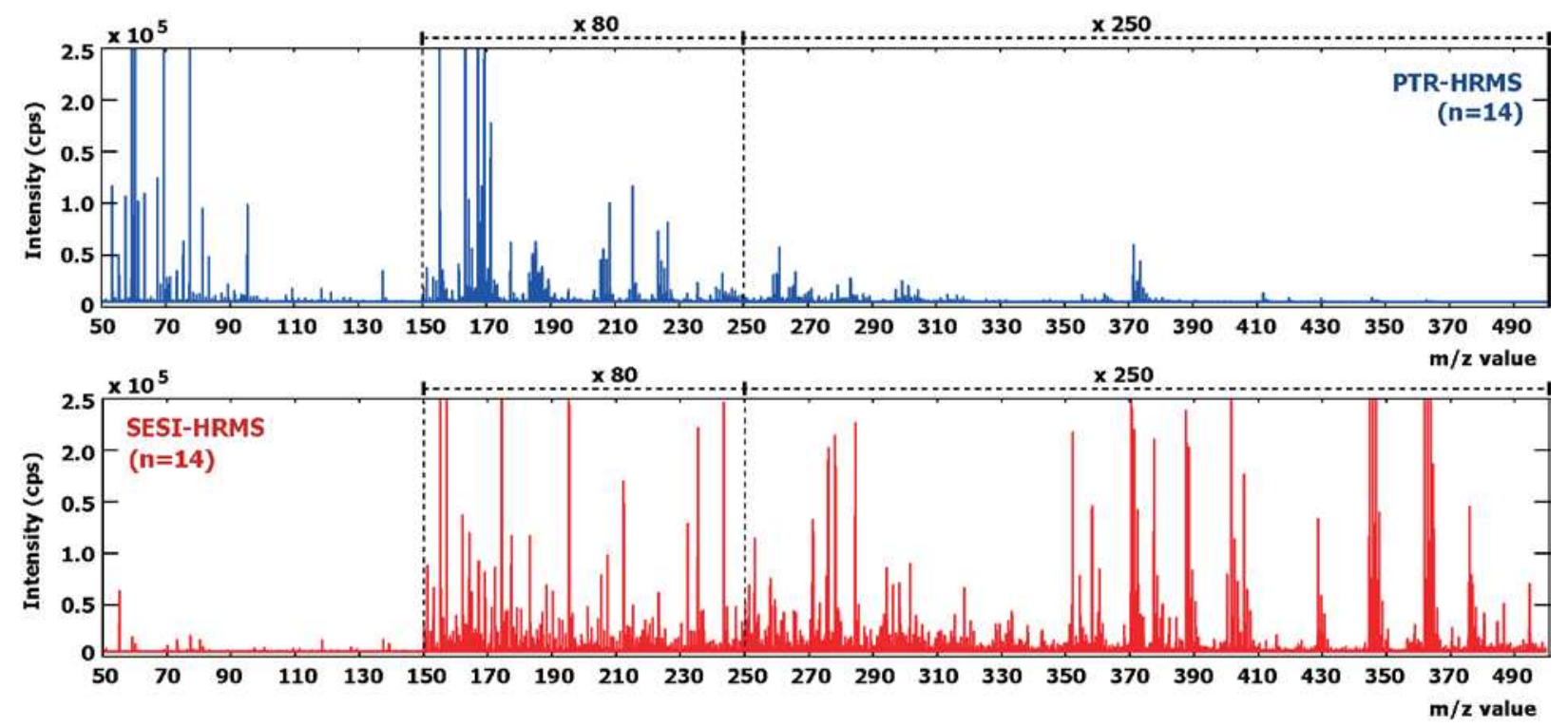

Figure 3: Comparison of mass spectra overlay for the average exhaled breath $m / z$ values for $\mathrm{n}=14$ subjects with a PTR and SESI time-of-flight high-resolution mass spectrometer (blue: PTR, red: SESI). The mass region $(\mathrm{m} / z=150-250)$ and the mass region $(\mathrm{m} / z 250-500)$ are magnified by a factor of $80 \mathrm{x}$ and $250 \mathrm{x}$, respectively.

\section{Comparison of detected breath $\mathrm{m} / z$ features}

Following the visual comparison of mass spectral trends, a more thorough investigation was conducted in a manner that was as unbiased as possible. Care was taken with the selection data analysis filters (see data analysis section). The same workflow and filters were applied for both instruments. Conservative filter thresholds were applied and samples were compared to a suitable background sample (i.e. simultaneously measured humid air. These filters resulted in significantly fewer, but probably more relevant, $\mathrm{m} / \mathrm{z}$ features than commonly reported for SESI (i.e. $828 \mathrm{~m} / \mathrm{z}$ features instead of usually approx. 3500 reported $\mathrm{m} / \mathrm{z}$ features) [9].

We can distinguish the following four groups: The unique PTR $\mathrm{m} / \mathrm{z}$ features (blue), the unique SESI $\mathrm{m} / \mathrm{z}$ features (red) and the shared ion species (green) including the matching $\mathrm{m} / \mathrm{z}$ features for SESI and PTR (+/-10 ppm) and the highly correlated ${ }^{13} \mathrm{C}$ isotopomers, adducts, or fragments (listed in Table S2; with a pair-wise Pearson's correlation coefficient $>0.95$ ). An example for a highly correlated $\mathrm{m} / \mathrm{z}$ feature is $\mathrm{m} / z, 77.0603$ for SESI which is the water adduct of the shared $\mathrm{m} / \mathrm{z}$ feature acetone with $\mathrm{m} / \mathrm{z}=59.0497$. All $\mathrm{m} / \mathrm{z}$ features are listed in Table S1 with the exception of the saturated features (i.e. acetone, and its two ${ }^{13} \mathrm{C}$ isotopomers for PTR). In total, $1304 \mathrm{~m} / \mathrm{z}$ features were detected with both methods (491 for PTR and 828 for SESI). There were 133 shared ion species with 102 matching $\mathrm{m} / \mathrm{z}$ features $( \pm 10$ ppm) and 31 related, highly correlated ${ }^{13} \mathrm{C}$ isotopomers, adducts, or fragments. The numbers of the remaining unique $\mathrm{m} / \mathrm{z}$ features were 374 for PTR and 797 for SESI. The results of the feature comparison are listed in Table 2.

Among the matching $\mathrm{m} / \mathrm{z}$ values for PTR, there were two highly correlated $\mathrm{CO}_{2}$ or $\mathrm{CO}$ losses and one ${ }^{13} \mathrm{C}$ isotopomer. Among the related, highly correlated features for PTR, there were $12{ }^{13} \mathrm{C}$ isotopomers and only one $\mathrm{NH}_{3}$ loss. Among the matching $\mathrm{m} / \mathrm{z}$ values for SESI, there were the following highly correlated features: four water adducts, four water losses, four $\mathrm{CO}$ or $\mathrm{CO}_{2}$ losses, one combined $\mathrm{CO}$ and water loss and one $\mathrm{NH}_{3}$ loss. Among the related, highly correlated features for SESI, there were seven ${ }^{13} \mathrm{C}$ isotopomers, five water adducts, four water losses, only one sodium adduct, and one ammonia loss.

Table 2: Comparison of the average number of breath $\mathrm{m} / \mathrm{z}$ features detected with a PTR and SESI time-of-flight highresolution mass spectrometer ( $\mathrm{n}=14$ subjects). Detailed information for each of the extracted $\mathrm{m} / \mathrm{z}$ features are listed in Table S1.

\begin{tabular}{lccc}
\hline & PTR-TOF & SESI-TOF \\
\hline Total $\boldsymbol{m} / \boldsymbol{z}$ features & & 1304 & \\
$\begin{array}{l}\text { Total } \boldsymbol{m} / \boldsymbol{z} \text { features } \\
\text { (for each method) }\end{array}$ & 491 & & 828 \\
Shared ion species & & 133 & \\
Unique $\boldsymbol{m} / \boldsymbol{z}$ features & 374 & & 797 \\
\hline
\end{tabular}



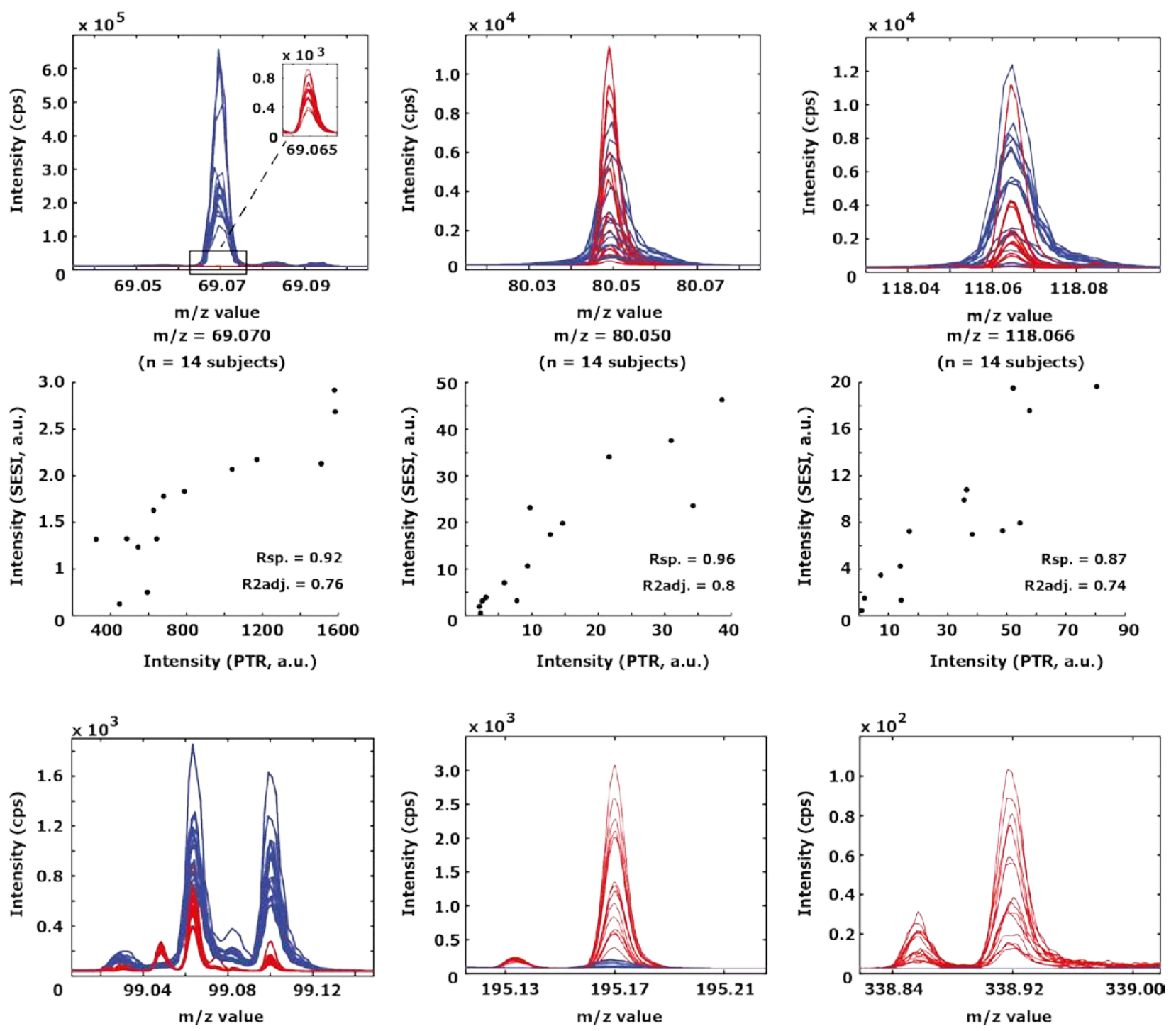

Figure 4: Example VOCs reported in exhaled breath shown as mass spectra overlay for all subjects $(\mathrm{n}=14)$ for both methods (red: SESI, blue: PTR). Top panel: $\mathrm{m} / z=69.070$ (isoprene, $\left.[\mathrm{C} 5 \mathrm{H} 8+\mathrm{H}]^{+}\right), \mathrm{m} / z=80.050\left(\right.$ pyridine, $[\mathrm{C} 5 \mathrm{H} 5 \mathrm{~N}+\mathrm{H}]^{+}$) and $\mathrm{m} / z=118.066$ (indole, $[\mathrm{C} 8 \mathrm{H} 7 \mathrm{~N}+\mathrm{H}]^{+}$). Mid panel: Isoprene, pyridine and indole showed linear correlations with Spearman's correlation coefficients of Rs. of 0.92, 0.96 and 0.87 and adjusted R2 of 0.76, 0.8 and 0.74. Each point in the bottom panel represents one subject $(\mathrm{n}=14$ subjects). Bottom panel: Several peaks in the following mass ranges: $m / z$ range $99.00-99.13$, $\mathrm{m} / \mathrm{z}$ range $195.12-195.21$ and $\mathrm{m} / \mathrm{z}$ range $338.80-339.02$.

The mass dependence for the detected $\mathrm{m} / \mathrm{z}$ features was further investigated and is presented in a condensed manner in figure 5. The average number of detected $\mathrm{m} / \mathrm{z}$ features was counted for nine $\mathrm{m} / \mathrm{z}$ regions with a width of $50 \mathrm{u} / \mathrm{e}$ each from $m / z, 50$ - 500. The numbers confirm the trend shown in figure 3 and give more insight into the differences between both ionization techniques. There are significantly more $\mathrm{m} / \mathrm{z}$ features for SESI in the high mass region, and most features in the very high mass region can only be detected with SESI. The detected number of $\mathrm{m} / \mathrm{z}$ features for the low mass region was comparable for both methods. For the very low mass region about two times more features can be detected with PTR than SESI and often with significantly higher intensities. Each of the detected $\mathrm{m} / \mathrm{z}$ features, their average intensity during exhalation and their group annotations are given in Table S1. 


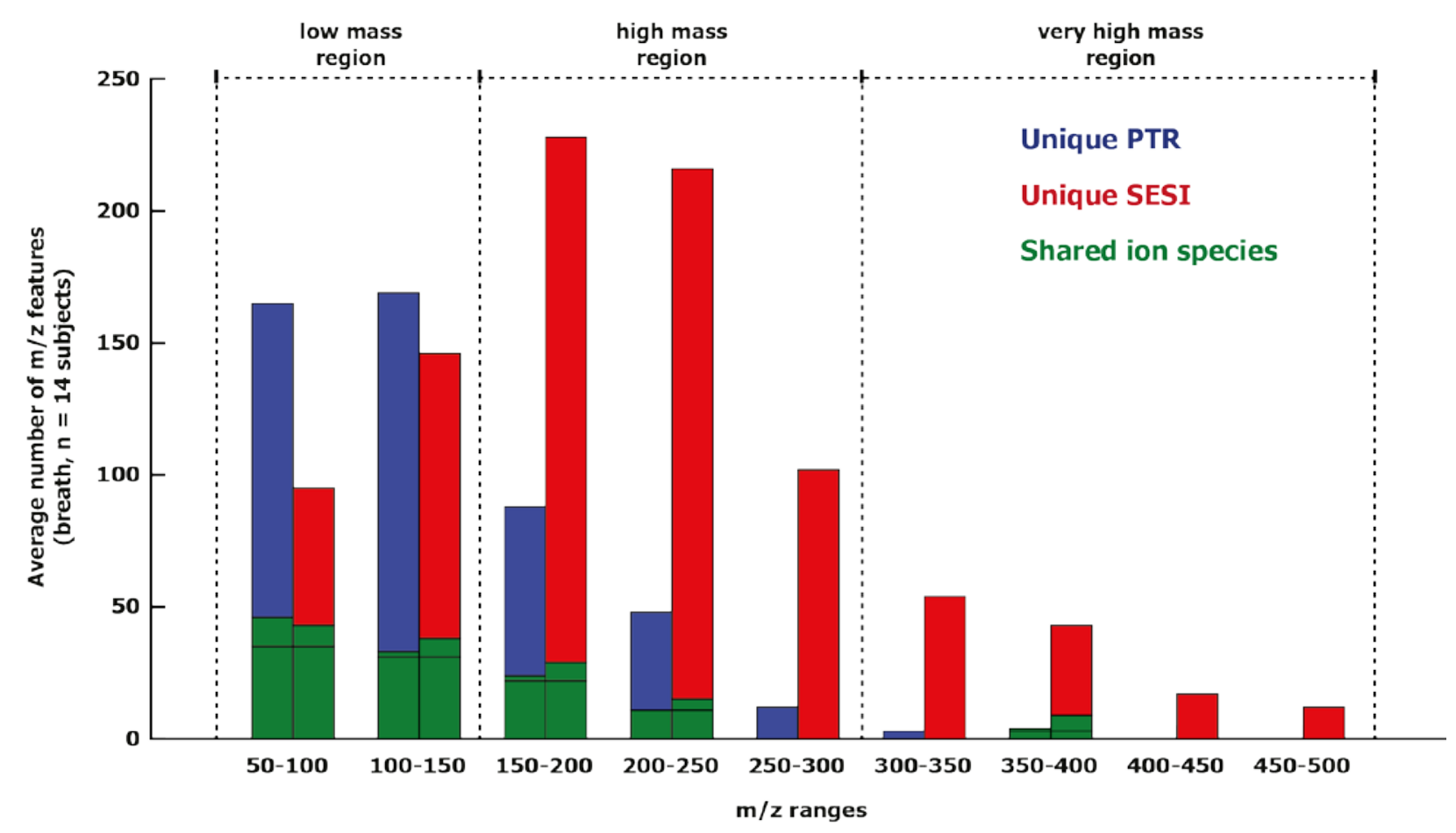

Figure 5: Comparison of the average number of $m / z$ features detected in exhaled breath with a PTR and SESI time-of-flight high-resolution mass spectrometry for $\mathrm{n}=14$ subjects. The $m / z$ features were binned by mass regions with a width of $50 \mathrm{u} / \mathrm{e}$ (blue: PTR, red: SESI, green: shared ion species including matching $\mathrm{m} / z$ features $(+/-10 \mathrm{ppm})$ andhighly correlated $\mathrm{m} / \mathrm{z}$ features (Pearson's correlation coeffficient > 0.95).

\section{Comparison of evaporated reference standards}

A library is available for the compounds which have been reported with PTR-MS [12] including aldehydes and ketones [18], alcohols [19], aromatic compounds [20], carboxylic acids [21], esters [22], terpenoids [23], alkenes [24], alkanes [25]. So far, amino acids have not been detected with PTR.

Recently, the compounds which can be detected with SESI-MS have been summarized [26]. These include aldehydes [27], ketones [28], alcohols [29], aromatic compounds, carboxylic acids [30], amino acids [31] as well as long-chain fatty acids [32]. Terpenoids, esters, alkenes or alkanes have so far not yet been reported with SESI and the detection of different chemical classes and the formation of adducts and fragments have not been systematically investigated for SESI. Therefore, we measured compounds from nine of the major chemical classes with the liquid standard evaporator system.

The results from the literature and from standards evaporator measurements for SESI are summarized in Table 3. The detailed results for the SESI standard evaporation measurements and the corresponding literature reports for PTR for each investigated compound is listed in Table S2.

Table 3: Reported chemical classes and principal ion liquid standard evaporation measurements (Table S2) or from the literature. n.r.: not reported

\begin{tabular}{|c|c|c|c|c|}
\hline \multirow{2}{*}{$\begin{array}{l}\text { Chemical } \\
\text { class }\end{array}$} & \multicolumn{2}{|c|}{ Detection } & \multicolumn{2}{|c|}{ Principal ion } \\
\hline & SESI & PTR & SESI & PTR \\
\hline Aldehydes & yes & yes & {$[\mathrm{M}+\mathrm{H}]^{+}$} & {$[\mathrm{M}+\mathrm{H}]^{+}$} \\
\hline Ketones & yes & yes & {$[\mathrm{M}+\mathrm{H}]^{+}$} & {$[\mathrm{M}+\mathrm{H}]^{+}$} \\
\hline Alcohols & yes & yes & {$[\mathrm{M}+\mathrm{H}]^{+}$} & $\begin{array}{c}{[\mathrm{M}+\mathrm{H}]^{+} \text {or }} \\
{[\mathrm{M}+\mathrm{H}-} \\
\left.\mathrm{H}_{2} \mathrm{O}\right]^{+}\end{array}$ \\
\hline $\begin{array}{l}\text { Aromatic } \\
\text { compounds }\end{array}$ & yes & yes & {$[\mathrm{M}+\mathrm{H}]^{+}$} & {$[\mathrm{M}+\mathrm{H}]^{+}$} \\
\hline $\begin{array}{l}\text { Carboxylic } \\
\text { acids }\end{array}$ & yes & yes & {$[\mathrm{M}+\mathrm{H}]^{+}$} & $\begin{array}{c}{[\mathrm{M}+\mathrm{H}]^{+} \text {or }} \\
\text { fragment }\end{array}$ \\
\hline Amino acids & yes & n. r. & $\begin{array}{l}{[\mathrm{M}+\mathrm{H}-} \\
\left.\mathrm{NH}_{3}\right]^{+}\end{array}$ & n. r. \\
\hline $\begin{array}{l}\text { Long chain } \\
\text { fatty acids }\end{array}$ & yes & yes & {$[\mathrm{M}+\mathrm{H}]^{+}$} & $\begin{array}{c}{[\mathrm{M}+\mathrm{H}]^{+} \text {or }} \\
\text { fragment }\end{array}$ \\
\hline Esters & yes & yes & {$[\mathrm{M}+\mathrm{H}]^{+}$} & $\begin{array}{c}{[\mathrm{M}+\mathrm{H}]^{+} \text {or }} \\
\text { fragment }\end{array}$ \\
\hline Terpenoids & yes & yes & {$[\mathrm{M}+\mathrm{H}]^{+}$} & $\begin{array}{c}{[\mathrm{M}+\mathrm{H}]^{+} \text {or }} \\
\text { fragment }\end{array}$ \\
\hline Alkanes & n. r. & yes & n. r. & $\begin{array}{c}{[\mathrm{M}+\mathrm{H}]^{+} \text {or }} \\
\text { fragment }\end{array}$ \\
\hline $\begin{array}{l}\text { Alkenes } \\
\text { (monoenes) }\end{array}$ & n. r. & $\begin{array}{c}\mathrm{C}_{8} \text { and } \\
\text { larger } \\
\text { (n-alkanes) }\end{array}$ & n. r. & $\begin{array}{c}{[\mathrm{M}+\mathrm{H}]^{+} \text {or }} \\
\text { fragment }\end{array}$ \\
\hline
\end{tabular}


For both methods the principal reported ion species is the singly protonated form with significant formation of fragments for PTR. The SESI measurements showed in addition, significant contributions of water adducts, sodium adducts and dimers for aldehydes; some water adducts for ketones, some dimers and sodium adducts for aromatic compounds; for acids the dominating form were water adducts followed by the singly protonated form. The amino acids showed a range of adducts and losses with the ammonia loss as the principal ion species followed by singly protonated form. Esters were mainly present as $[\mathrm{M}+\mathrm{H}]^{+}$with significant amounts of sodium dimers. Terpenoids were mainly detected as $[\mathrm{M}+\mathrm{H}]^{+}$with some contributions from water adducts. Alkenes and Alkanes could not be detected with the investigated relatively low amounts of compounds. Overall there were significant contributions of water adducts detected for SESI for the liquid evaporator measurements. A possible cause might be collisions in the medium pressure region of the Q-TOF mass spectrometers even with the zero collision gas setting (see instrumentation section).

\section{Hypotheses for the observed differences between SESI and PTR}

The overall higher number of detected $\mathrm{m} / \mathrm{z}$ features in breath indicate a higher sensitivity for the investigated SESI-TOF instrument compared to the PTR-TOF

instrument. The evaporated reference standards measured with SESI show that multiple ion species are possible. In breath, the contribution from adducts and fragments for the subset of 102 matching $\mathrm{m} / \mathrm{z}$ features between both methods and the related, highly correlated $31 \mathrm{~m} / \mathrm{z}$ features, there were only two $\mathrm{CO}_{2}$ or $\mathrm{CO}$ losses and one $\mathrm{NH}_{3}$ loss assigned for PTR. However, for SESI, there were a total of five water adducts and only one sodium adduct; eight water losses, four $\mathrm{CO}$ or $\mathrm{CO}_{2}$ losses, two $\mathrm{NH}_{3}$ losses, one combined $\mathrm{CO} /$ water loss. This indicates that a larger part of the detected $\mathrm{m} / \mathrm{z}$ values for SESI than for PTR could originate from redundant, different ion forms of the same molecules.

For the low mass range in breath, several $\mathrm{m} / \mathrm{z}$ features are significantly lower for SESI than for PTR. In the low mass region of the PTR spectra, fragments might be present. However, fragmentation does not appear to be a major contributor, and does not compromise our hypothesis. For instance, isoprene (in the low mass region) shows a good signal correlation between PTR and SESI (Figure 4), while PTR has about 57 times higher signals for this compound Table 4). We hypothesize that for these compounds there are not sufficient charges available anymore (ion suppression in SESI). If ion suppression is a factor, then the compounds with lowest proton affinities would be affected first. The significantly lower intensities for some compounds with low proton affinities in the low mass region such as acetone and isoprene $(\mathrm{PA}=812.0$ and 826.4 $\mathrm{kJ} / \mathrm{mol}$, respectively) and comparable intensities for pyridine and indole with high proton affinities $(\mathrm{PA}=930.0$ and $933.4 \mathrm{~kJ} / \mathrm{mol}$, respectively) indicate that ion suppression might indeed play a role [27]. As a reference point, the proton affinity of water is $690 \pm 4 \mathrm{~kJ} / \mathrm{mol}$ and that of the water dimer is $808 \pm 4 \mathrm{~kJ} / \mathrm{mol}$ [28].

We further investigated the behavior of a subset of known breath volatiles with known proton affinities. The volatilome list of the United States Environmental Protection Agency (EPA) was used as a reference point which contains 1075 compounds which have been reported in breath [29]. Only entries with a reported proton affinity by the United States National Institute of Standards and Technology (NIST) were considered [27]. This resulted in a list of 48 compounds that could potentially be detected by either SESI or PTR. To avoid ambiguity, only matches with a single reported isomeric form were considered, which resulted in a final list of 18 annotated compounds (see Table $4)$. The compounds with low proton affinity ( $<450 \mathrm{~kJ} / \mathrm{mol})$ showed significantly higher intensities for PTR than SESI (> 10x) while the compounds with high proton affinity (> $450 \mathrm{~kJ} / \mathrm{ml}$ ) showed comparable intensities for PTR and SESI $(<2 \mathrm{x})$ or could only be detected by SESI. The results listed in Table 4 are an indication that for SESI the compounds with low proton affinities might be affected by ion suppression effects. Acetone follows the same trend but has been excluded from the table due it being saturated during the PTR measurements.

Compound class dependent differences in ionization for PTR compared to SESI might further explain some of the observed differences.

Table 4: Reported breath volatiles (EPA's volatilome list, [29]) with listed proton affinities (NIST, [27]) which could be detected in exhaled breath by either SESI or PTR analysis. The significantly higher intensities PTR/SESI with proton affinities $<450 \mathrm{kj} / \mathrm{mol}$ are highlighted in red. $*$ The intensities for PTR resp. SESI in a.u. are reported in brackets. PA: Proton Affinity.

\begin{tabular}{|c|c|c|c|c|}
\hline $\mathbf{N r}$ & Compound & $\begin{array}{c}\text { Exact mass } \\
{[\mathbf{M}+\mathbf{H}]^{+}}\end{array}$ & $\underset{(\mathrm{kJ} / \mathrm{mol})}{\text { PA }}$ & $\begin{array}{c}\text { Intensity ratio } \\
\text { PTR/SESI* }\end{array}$ \\
\hline 1 & Phenol & 95.049 & 817.3 & $29.0(8.4 \mathrm{e} 3 / 2.9 \mathrm{e} 2)$ \\
\hline 2 & $\begin{array}{l}\text { 1,3-Cyclo- } \\
\text { pentadiene }\end{array}$ & 67.054 & 821.6 & $297.9(1.4 \mathrm{e} 4 / 4.7 \mathrm{e} 1)$ \\
\hline 3 & Isoprene & 69.069 & 826.4 & $56.8(2.5 \mathrm{e} 4 / 4.4 \mathrm{e} 2)$ \\
\hline 4 & $\begin{array}{l}\text { 1,3-Cyclo- } \\
\text { hexadiene }\end{array}$ & 81.069 & 837 & $14.2(7.5 \mathrm{e} 3 / 5.3 \mathrm{e} 2)$ \\
\hline 5 & 4-Heptanone & 115.111 & 845 & $12.6(2.4 \mathrm{e} 2 / 1.9 \mathrm{e} 1)$ \\
\hline 6 & Camphor & 153.127 & 859.2 & $0.5(1.1 \mathrm{e} 2 / 2.2 \mathrm{e} 2)$ \\
\hline 7 & Pyrrole & 68.049 & 875.4 & Unique SESI (2.2e1) \\
\hline 8 & Aniline & 94.065 & 882.5 & Unique SESI (9.4e1) \\
\hline 9 & $\begin{array}{l}\text { Dimethyl } \\
\text { sulfoxide }\end{array}$ & 79.021 & 884.4 & Unique SESI (2.0e2) \\
\hline 10 & Glycine & 76.039 & 886.5 & $1.7(1.5 \mathrm{e} 2 / 8.6 \mathrm{e} 1)$ \\
\hline
\end{tabular}




\begin{tabular}{|c|c|c|c|c|}
\hline 11 & Alanine & 90.054 & 901.6 & Unique SESI (4.9e1) \\
\hline 12 & $\begin{array}{l}\text { Dimethyl- } \\
\text { acetamide }\end{array}$ & 88.075 & 908 & Unique SESI (1.4e2) \\
\hline 13 & Valine & 118.086 & 910.6 & Unique SESI (2.0e2) \\
\hline 14 & Leucine & 132.101 & 914.6 & Unique SESI (1.9e2) \\
\hline 15 & Proline & 116.07 & 920.5 & Unique SESI (1.4e2) \\
\hline 16 & Phenylalanine & 166.086 & 922.9 & Unique SESI (3.1e1) \\
\hline 17 & Pyridine & 80.049 & 930 & $0.5(2.4 \mathrm{e} 3 / 1.1 \mathrm{e} 3)$ \\
\hline 18 & Indole & 118.065 & 933.4 & $1.4(2.6 \mathrm{e} 3 / 1.8 \mathrm{e} 3)$ \\
\hline
\end{tabular}

\section{Conclusions}

In a direct comparison of two state-of-the-art PTR-MS and SESI-MS instruments, a clear mass dependence was observed for each method with the highest number of detected $\mathrm{m} / \mathrm{z}$ features for SESI in the high mass region $(\mathrm{m} / \mathrm{z}$ $150-250)$ and for PTR in the low mass region $(\mathrm{m} / z 50-$ 150). In particular, most compounds in the very high mass region $(\mathrm{m} / z, 300-500)$ could only be detected with SESI. The numbers for the low mass region $(\mathrm{m} / z, 100$ - 150) were comparable. However, in the very low mass region $(\mathrm{m} / z 50$ $-100)$ there were significantly more features for PTR, often with significantly higher intensities.

Significantly higher feature numbers were observed for SESI than for PTR with 797 vs. 374 unique features of a total of 1304 total $\mathrm{m} / \mathrm{z}$ features detected in exhaled breath. The number of common ion species was lower than expected with 131 features. Hypotheses to explain the observed mass dependent differences have been put forth.

Our hypothesis is that the main driver for this mass dependence is a higher sensitivity for the SESI than the PTR instrument. However, it seems that there are not enough charges available anymore for some compounds in the low mass region for SESI (possible ion suppression effects). This is supported by the observation that for a set of known breath volatiles, the compounds with lower proton affinities are detected at significantly lower intensities for SESI compared to PTR. Furthermore, a greater number of redundant, multiple ion forms for the same molecules could be assigned for SESI than for PTR for the subset of 133 matching ion species between both methods. These factors together might explain the main differences between the two methods.

\section{Acknowledgments}

This work is part of the Zurich Exhalomics flagship project under the umbrella of "University Medicine Zurich/Hochschulmedizin Zürich". TB, AM thank the Uniscientia foundation for partial financial support of this work. LC acknowledges funding from PDiSC\#02BIRD2019-UNIPD. We acknowledge Christian Marro from the workshop at ETH Zurich for fabricating the custom-made evaporator/humidifier system. Furthermore, TB would like to thank the volunteers who participated for this study from the pulmonology and clinical chemistry groups at the University Children's Hospital Zurich, the pulmonology group at the University Hospital Zurich, and the Zenobi group at ETH Zurich.

\section{Supplementary Material}

Electronic supplementary information is available online. Data used in this publication will be made freely accessible in a curated data archive at ETH Zurich (https://www.research-collection.ethz.ch) under the DOI 10.3929/ethz-b-000400581

\section{References}

1. Yuan, B., Koss, A.R., Warneke, C., Coggon, M., Sekimoto, K., De Gouw, J.A.: Proton-Transfer-Reaction Mass Spectrometry: Applications in Atmospheric Sciences. Chem. Rev. 117, 13187-13229 (2017). https://doi.org/10.1021/acs.chemrev.7b00325

2. Giannoukos, S., Brkić, B., Taylor, S., Marshall, A., Verbeck, G.F.: Chemical Sniffing Instrumentation for Security Applications. Chem. Rev. 116, 8146-8172 (2016). https://doi.org/10.1021/acs.chemrev.6b00065

3. Wallace, M.A.G., Pleil, J.D.: Evolution of clinical and environmental health applications of exhaled breath research: Review of methods and instrumentation for gasphase, condensate, and aerosols, (2018)

4. Bruderer, T., Gaisl, T., Gaugg, M.T., Nowak, N., Streckenbach, B., Müller, S., Moeller, A., Kohler, M., Zenobi, R.: On-Line Analysis of Exhaled Breath, (2019)

5. Gaugg, M.T., Gomez, D.G., Barrios-Collado, C., Vidalde-Miguel, G., Kohler, M., Zenobi, R., Martinez-Lozano Sinues, P.: Expanding metabolite coverage of real-time breath analysis by coupling a universal secondary electrospray ionization source and high resolution mass spectrometry - a pilot study on tobacco smokers. J. Breath Res. 10, $016010 \quad$ (2016). https://doi.org/10.1088/1752-7155/10/1/016010

6. Jordan, A., Haidacher, S., Hanel, G., Hartungen, E., Märk, L., Seehauser, H., Schottkowsky, R., Sulzer, P., Märk, T.D.: A high resolution and high sensitivity protontransfer-reaction time-of-flight mass spectrometer (PTRTOF-MS). Int. J. Mass Spectrom. 286, 122-128 (2009). https://doi.org/10.1016/j.ijms.2009.07.005

7. Krechmer, J., Lopez-Hilfiker, F., Koss, A., Hutterli, M., Stoermer, C., Deming, B., Kimmel, J., Warneke, C., Holzinger, R., Jayne, J., Worsnop, D., Fuhrer, K., Gonin, M., de Gouw, J.: Evaluation of a New Reagent-Ion Source and Focusing Ion-Molecule Reactor for Use in 
Proton-Transfer-Reaction Mass Spectrometry. Anal. Chem. 90, 12011-12018 (2018). https://doi.org/10.1021/acs.analchem.8b02641

8. Singh, K.D., Tancev, G., Decrue, F., Usemann, J., Appenzeller, R., Barreiro, P., Jaumà, G., Macia Santiago, M., Vidal de Miguel, G., Frey, U., Sinues, P.: Standardization procedures for real-time breath analysis by secondary electrospray ionization high-resolution mass spectrometry. Anal. Bioanal. Chem. 411, 4883-4898 (2019). https://doi.org/10.1007/s00216-019-01764-8

9. Weber, R., Haas, N., Baghdasaryan, A., Bruderer, T., Inci, D., Micic, S., Perkins, N., Spinas, R., Zenobi, R.: Volatile organic compound breath signatures of children with cystic fibrosis by real-time SESI-HRMS. https://doi.org/10.1183/23120541.00171-2019

10. Chambers, M.C., MacLean, B., Burke, R., Amodei, D., Ruderman, D.L., Neumann, S., Gatto, L., Fischer, B., Pratt, B., Egertson, J., Hoff, K., Kessner, D., Tasman, N., Shulman, N., Frewen, B., Baker, T.A., Brusniak, M.Y., Paulse, C., Creasy, D., Flashner, L., Kani, K., Moulding, C., Seymour, S.L., Nuwaysir, L.M., Lefebvre, B., Kuhlmann, F., Roark, J., Rainer, P., Detlev, S., Hemenway, T., Huhmer, A., Langridge, J., Connolly, B., Chadick, T., Holly, K., Eckels, J., Deutsch, E.W., Moritz, R.L., Katz, J.E., Agus, D.B., MacCoss, M., Tabb, D.L., Mallick, P.: A cross-platform toolkit for mass spectrometry and proteomics. Nat. Biotechnol. 30, 918920 (2012). https://doi.org/10.1038/nbt.2377

11. Caporaso, N., Whitworth, M.B., Cui, C., Fisk, I.D.: Variability of single bean coffee volatile compounds of Arabica and robusta roasted coffees analysed by SPMEGC-MS. Food Res. Int. (2018). https://doi.org/10.1016/j.foodres.2018.03.077

12. Pagonis, D., Sekimoto, K., de Gouw, J.: A Library of Proton-Transfer Reactions of $\mathrm{H} 3 \mathrm{O}+$ Ions Used for Trace Gas Detection. J. Am. Soc. Mass Spectrom. 30, 13301335 (2019). https://doi.org/10.1007/s13361-019-02209-3

13. Blake, R.S., Patel, M., Monks, P.S., Ellis, A.M., Inomata, S., Tanimoto, H.: Aldehyde and ketone discrimination and quantification using two-stage proton transfer reaction mass spectrometry. Int. J. Mass Spectrom. 278, 15-19 (2008). https://doi.org/10.1016/j.ijms.2008.07.010

14. Wang, T., Španěl, P., Smith, D.: A selected ion flow tube study of the reactions of $\mathrm{H} 3 \mathrm{O}+, \mathrm{NO}+$ and $\mathrm{O} 2+\bullet$ with some phenols, phenyl alcohols and cyclic carbonyl compounds in support of SIFT-MS and PTR-MS. Int. J. Mass Spectrom. 239, 139-146 (2004). https://doi.org/10.1016/j.ijms.2004.07.022

15. Jobson, B.T., Volkamer, R.A., Velasco, E., Allwine, G.,
Westberg, H., Lamb, B.K., Alexander, M.L., Berkowitz, C.M., Molina, L.T.: Comparison of aromatic hydrocarbon measurements made by PTR-MS, DOAS and GC-FID during the MCMA 2003 Field Experiment. Atmos. Chem. Phys. 10, 1989-2005 (2010). https://doi.org/10.5194/acp10-1989-2010

16. Hartungen, E. Von, Wisthaler, A., Mikoviny, T., Jaksch, D., Boscaini, E., Dunphy, P.J., Märk, T.D.: Protontransfer-reaction mass spectrometry (PTR-MS) of carboxylic acids: Determination of Henry's law constants and axillary odour investigations. Int. J. Mass Spectrom. (2004). https://doi.org/10.1016/j.ijms.2004.09.009

17. Aprea, E., Biasioli, F., Märk, T.D., Gasperi, F.: PTR-MS study of esters in water and water/ethanol solutions: Fragmentation patterns and partition coefficients. Int. J. Mass Spectrom. 262, 114-121 (2007). https://doi.org/10.1016/j.ijms.2006.10.016

18. Schuhfried, E., Aprea, E., Märk, T.D., Biasioli, F.: Refined measurements of Henry's law constant of terpenes with inert gas stripping coupled with PTR-MS. Water. Air. Soil Pollut. 226, (2015). https://doi.org/10.1007/s11270-015-2337-2

19. Gueneron, M., Erickson, M.H., Vanderschelden, G.S., Jobson, B.T.: PTR-MS fragmentation patterns of gasoline hydrocarbons. Int. J. Mass Spectrom. 379, 97-109 (2015). https://doi.org/10.1016/j.ijms.2015.01.001

20. Erickson, M.H., Gueneron, M., Jobson, B.T.: Measuring long chain alkanes in diesel engine exhaust by thermal desorption PTR-MS. Atmos. Meas. Tech. 7, 225-239 (2014). https://doi.org/10.5194/amt-7-225-2014

21. Bruderer, T., Gaisl, T., T. Gaugg, M., Nowak, N., Streckenbach, B., Müller, S., Moeller, A., Kohler, M., Zenobi, R.: On-Line Analysis of Exhaled Breath. Chem. Rev. 119, 10803-10828 (2019). https://doi.org/10.1021/acs.chemrev.9b00005

22. García-Gómez, D., Gaisl, T., Bregy, L., Martínez-Lozano Sinues, P., Kohler, M., Zenobi, R.: Secondary electrospray ionization coupled to high-resolution mass spectrometry reveals tryptophan pathway metabolites in exhaled human breath. Chem. Commun. 52, 8526-8528 (2016). https://doi.org/10.1039/C6CC03070J

23. Zhu, J.J., Bean, H.D., Kuo, Y.M., Hill, J.E.: Fast Detection of Volatile Organic Compounds from Bacterial Cultures by Secondary Electrospray Ionization-Mass Spectrometry. J. Clin. Microbiol. 48, 4426-4431 (2010). https://doi.org/10.1128/jcm.00392-10

24. Tejero Rioseras, A., Singh, K.D., Nowak, N., Gaugg, M.T., Bruderer, T., Zenobi, R., Sinues, P.M.-L.: Real- 
Time Monitoring of Tricarboxylic Acid Metabolites in Exhaled Breath. Anal. Chem. 90, 6453-6460 (2018). https://doi.org/10.1021/acs.analchem.7b04600

25. Gaugg, M.T., Engler, A., Bregy, L., NussbaumerOchsner, Y., Eiffert, L., Bruderer, T., Zenobi, R., Sinues, P., Kohler, M.: Molecular breath analysis supports altered amino acid metabolism in idiopathic pulmonary fibrosis. Respirology. 0,. https://doi.org/10.1111/resp.13465

26. Gaugg, M.T., Bruderer, T., Nowak, N., Eiffert, L., Sinues, P.M.-L., Kohler, M., Zenobi, R.: Mass-Spectrometric Detection of Omega-Oxidation Products of AliphaticFatty Acids in Exhaled Breath. Anal. Chem. 89, 10329-10334 (2017). https://doi.org/10.1021/acs.analchem.7b02092

27. EPA: NIST Proton Affinity Search, https://webbook.nist.gov/chemistry/pa-ser/

28. Goebbert, D.J., Wenthold, P.G.: Water Dimer Proton Affinity from the Kinetic Method: Dissociation Energy of the Water Dimer. Eur. J. Mass Spectrom. 10, 837-845 (2004). https://doi.org/10.1255/ejms.684

29. Pleil, J.D.: VOLATILOME: Human Breath, https://comptox.epa.gov/dashboard/chemical_lists/VOLA TILOME 